\title{
Carlos Casale
}

Facultad de Teología

Pontificia Universidad Católica de Chile

\section{Balthasar y la metafísica del "ser donado" (1)}

En el presente artículo queremos mostrar cómo Heidegger ha tenido un influjo clave en uno de los aspectos decisivos del pensamiento balthasariano, como lo es analizar la dimensión "horizontal" del drama entre Dios y el hombre, dimensión por cierto abierta al acontecer de Dios en la historia. Es así sobre todo pensando a Dios como un evento, un acontecimiento que tiene lugar en la historia y sobre todo al interior del desenvolvimiento del ser humano concreto al interior de ésta como ser libre, como aparecerá en uno de los motivos centrales de la teología de Balthasar la influencia del pensador de Friburgo.

Desde un punto de vista cuantitativo, pero sobre todo cualitativo, Heidegger -junto con Hegel, Schelling, Ulrich y Husserl- es ciertamente uno de los filósofos preferidos de Balthasar (habría que nombrar aquí también a Goethe, quien no siendo estrictamente un filósofo, influyó decisivamente a nuestro autor, especialmente en su cercanía a la fenomenología) (2).

Desde sus inicios, Balthasar le había dedicado ya numerosos artículos y partes de libros a Heidegger. No es así de asombrarse que más tarde nos encontremos con una importante sección enteramente dedicada a Heidegger en el volumen de Gloria donde nuestro autor trata la metafísica moderna. Es de esta manera que el teólogo de Basilea, consciente de los límites del pensamiento heideggeriano en cuanto al reconocimiento "personal" del ser, admite sin embargo que gracias particularmente a la

(1) Este artículo es resultado de una investigación que se ha llevado a cabo en el marco del proyecto FONDECYT 1071047: "El análisis fenomenológico de la vida fáctica del joven Heidegger en las primeras lecciones de Friburgo (1919-1923) como desafío a la teología actual”.

(2) Para una visión más amplia de las influencias filosóficas en Balthasar cf. E. J. Bauer, Hans Urs von Balthasar, en: AAVV, Filosofía cristiana en el pensamiento católico de los siglos XIX y XX, vol. 3, Corrientes modernas en el siglo XX, Madrid 1997, 268-286; J. Villagrasa, Hans Urs von Balthasar, filósofo, Alpha Omega 3 (2005), 475-502; M. Schulz, Hans Urs von Balthasar begegnen, Augsburg 2002; Ph. Capelle, Hans Urs von Balthasar: comment regagner une philosophie à partir de la théologie, en: H.-J. Gagey/V. Holzer (eds.), Balthasar, Rahner. Deus pensées en contraste, Paris 2005, 97-116; G. Narcisse, I fondamenti filosofici della teologia di Hans Urs von Balthasar, Communio (Milano) 30 (2005), 44-51; E. Prato, Senza filosofia nessuna teologia. Identità cristiana e filosofia in Hans Urs von Balthasar, en: G. Ferretti (ed.), Identità cristiana e filosofia, Torino 2002, 329-344; A. Meis, Razón y amor en la Teológica de Hans Urs von Balthasar, Teología y Vida XLV (2004), 104-136; A. Brugnoli, Hans Urs von Balthasar e il rapporto tra filosofia e fedecristiana, Sensus communis 2 (2001), 253-262. 
puesta en evidencia de la "distinción real" (distinctio realis) operada por el filósofo alemán, éste es el partner contemporáneo más fecundo en vista a la elaboración de una estética teológica: "Yo no puedo calmar mi asombro originario-universal (que existe en general algo) mediante mi mirada al ser por cuya participación los entes son. Más bien mi asombro se vuelve a los dos términos de la diferencia ontológica, tanto si se concibe como Tomás o como Heidegger, ya que el hecho de que el ente sólo puede ser real mediante la participación en el acto de ser, remite a la antítesis integradora de que la plenitud del ser sólo llega a ser real en el ente singular; pero el hecho de que el ser (heideggeriano) pueda explicarse sólo en la existencia (espíritu) comprende la dependencia del ser con respecto a lo existente y, de este modo, su nosubsistencia" (3).

Sin embargo, las referencias a Heidegger en la Trilogía no se limitan a la Estética, pues Balthasar se referirá en dos lugares al filósofo alemán en La acción. El papel desempeñado por Heidegger en la primera parte de la Trilogía está bien estudiado (4), sin embargo, el lugar táctico que Balthasar le atribuye en la lógica y la estructura formal de la Teodramática y su significación han merecido menos atención (5) (es de notar que las reflexiones de Gloria y Teodramática en relación a Heidegger están sutilmente unidas por la idea de "alteridad" como constitutiva de lo finito espiritual, lo cual se revela en su grado máximo en relación a la alteridad frente a la divinidad, que en el caso de la dramática, es la alteridad frente a la acción de Dios que llama a mi acción, en una notable analogía con el mundo del teatro). Tomando en cuenta que estas citas están al interior del centro estructurante de su pensamiento, el acontecer real y patético de Dios en la historia que llama al hombre a una respuesta, en las siguientes reflexiones queremos aludir sintéticamente a este lugar táctico.

En un primer momento (1) señalaremos el lugar central de la Teodramática al interior de la Trilogía -y por ello en la obra total de Balthasar, por ser aquella su obra cumbre- y al papel que desempeña en el núcleo de la dramática el volumen dedicado a La acción. En un segundo momento (2), veremos brevemente la relevancia de las citas de Ser y tiempo en el volumen tercero de la Teodramática, para pasar luego (3-6) a las referencias que lleva a cabo el teólogo suizo de Heidegger, como lo es la apropiación teológica de la interpretación que el filósofo alemán realiza de Nietzsche en su obra homónima. Aquí planteamos un diálogo crítico-prospectivo con Balthasar. Finalmente en una conclusión plantearemos algunas preguntas para seguir reflexionando.

(3) Herrlichkeit. Im Raum der Methaphysik, vol. III/1, Einsiedeln 1965, 949 (Gloria. Una estética teológica, vol. V, Metafísica. Edad moderna, Madrid 1996, 568).

(4) Cf. J. Villagrasa, La metafísica de Hans Urs von Balthasar, Alpha Omega 3 (2007), 319-354; E. Pérez Haro, El misterio del ser. Una mediación entre filosofía y teología en Hans Urs von Balthasar, Barcelona 1994; P. De Vitiis, Estetica teologica e questione dell'essere: Balthasar e Heidegger, en: Esperienza estetica e teologia, Brescia 2003, 123-142; id., Prospettive heideggeriane, Brescia 2006, 161-181.

(5) $C f$. los importantes y sugerentes estudios de M. Imperatori, Heidegger dans la "Dramatique divine" de Hans Urs von Balthasar, Nouvelle revue théologique 122 (2000), 191-210; id., H. U. von Balthasar: una teologia drammatica della storia. Per un discernimento dialogico nella modernità, Roma 2001; ver también J. Villagrasa, La metafísica de Hans Urs von Balthasar, 319-354; A. Chapelle, La maravilla del ser. La filosofía y la gloria, Communio (Madrid) 11 (1989), 407-413. 


\section{ELEMENTOS ESTRUCTURALES DE LA TEODRAMÁTICA}

Desde un punto de vista "arquitectónico" lo primero que hay que afirmar es que la Trilogía es un tríptico... "Un tríptico es otra cosa que una trilogía... No solamente porque uno pertenece a la pintura y el otro a la literatura o la música, sino porque la trilogía señala un pasaje sucesivo y contenido, en suma, homogéneo, de una parte a la otra, en tanto que el tríptico consiste, más estáticamente, en un parte central y dominante, rodeada de dos alas a la derecha y a la izquierda, normalmente móviles y secundarias, que tienen la función de realzar y de interpretar la tabla del medio... es un tríptico donde la parte central, la 'Teodramática', ocupa no sólo el medio, sino es central así en el sentido que ella es la más importante, puesto que contiene el verdadero mensaje (véritable mesagge) de la trilogía teológica y de la cual las dos otras partes dependen" (6).

Dentro de la dramática divina el volumen La acción forma el núcleo estructurante de la obra.

Es importante señalar para nuestras reflexiones que la estructura de La acción, título que ya nos adelanta la idea de un Dios que acontece y en este acontecer revela su ser, está compuesta de cuatro partes: en una primera se trata el tema de la relación entre tiempo y eternidad en el Apocalipsis, a modo de hilo conductor y "obertura" del drama. Es así, en efecto, que pone la base de una articulación dramática entre una dimensión horizontal y dimensión vertical (7). Esta primera parte es seguida de una segunda, en una suerte de paréntesis metódico parcial, encargado de ilustrar la dimensión puramente horizontal del drama, antes de llegar en la tercera a mostrar cómo Dios interviene, como el evento escatológico, en la "escena del mundo" para salvarlo a través de su "inhabitación" en la libertad del hombre que así queda liberada para vivir su auténtica autonomía (8). En la cuarta, nuestro autor se preocupará de mostrar, a la luz de todo lo que ha sido desarrollado anteriormente, cómo el hombre y Dios se reencuentran en la historia puesta bajo el signo apocalíptico de la "batalla del logos" (9).

Nuestra intención es pues mostrar a continuación cómo la filosofía de Heidegger le entrega a Balthasar elementos para pensar a Dios sobre todo como evento, como acontecimiento que, aunque se revela en el plano así llamado horizontal del teodrama, permite realizar una hermenéutica de este "plano" desde la perspectiva del Dios que se da al hombre.

(6) P. Henrici, La structure de la Trilogie de Hans Urs von Balthasar, Transversalites 63 (1997), 17; E. Biser, Dombau oder Triptychon? Zum Abschluß der Trilogie Hans Urs von Balthasar, Theologische Revue 84 (1986), 177-184; V. Holzer, Les implications métaphysico-religieuses d'une dramatique trinitaire chez Hans Urs von Balthasar, Gregorianum 2 (2005), 308-329; S. Ponga, La dramatique trinitaire de la révélation et du salud chez H. U. von Balthasar, Nouvelle revue théologique 124 (2002), 549-564; C. Dumont, “Action” et "Dénouement” dans la "Dramatique” de H. U. von Balthasar, Nouvelle revue théologique 116 (1994), 727-736.

(7) Cf. Theodramatik, vol. III, Die Handlung, Einsiedeln 1980, 27 (Teodramática, vol. 4, La acción, Madrid 1995, 30-31).

(8) Cf. ibid., 189-395 (185-292).

(9) Cf. ibid., 399-468 (397-474). 


\section{ALGUNOS ASPECTOS DE LA ANALÍTICA HEIDEGGERIANA DEL DASEIN EN LA ACCIÓN}

Es sobre todo en Gloria donde Balthasar acomete un estudio largo y profundo de las ideas de Ser y tiempo leídas desde la teología. Sin embargo, las breves referencias en la Teodramática a esta obra filosófica son claves para hacer una hermenéutica de la autocomprensión del hombre moderno frente a su finitud, y abrir así la posibilidad de un diálogo con la teología. Las dos referencias que la Teodramática hace de Heidegger se hallan en la segunda parte de La acción, la que se ocupa de caracterizar la dimensión horizontal del drama de la existencia humana haciendo abstracción, en la medida de lo posible, de los antecedentes de la revelación cristiana, los cuales reaparecen solamente hacia el final de esta misma parte, cuando nuestro teólogo se preocupará de iluminar el misterio del mal y del pecado. Balthasar cita al filósofo alemán al inicio de la tercera sección del libro, dedicada al análisis de las relaciones entre el tiempo y la muerte. Balthasar utiliza de esta forma una parte del análisis ontológico del Dasein de Ser y tiempo para subrayar la finitud radical que caracteriza la vida humana, y eso en oposición explícita a los titanismos (10) de las grandes ideologías. Como muy bien señala nuestro autor en El todo en el fragmento, una obra que en parte resume las intuiciones básicas de la Trilogía y en especial de la Teodramática: "A quien intenta hoy reflexionar y hablar sobre Dios y sobre el hombre, en obediencia a la Palabra de Dios, se le presenta la difícil tarea de recorrer el estrecho sendero que pasa entre dos modalidades de titanismo... La otra, la nueva, consiste en la identificación -o por lo menos en el planteamiento de una convergencia- entre el progreso técnico del mundo y el desarrollo del Reino de Dios. Ambas son, no obstante, como veremos, únicamente formas lúdicas del mismo integrismo... Ambos intentan procurar un poder terreno al Reino del Crucificado, dado que ambos mezclan reino terreno y reino divino. Los antiguos, por el hecho de ver el reino invisible representado simbólicamente en uno visible; los modernos, por el hecho de reducir lo invisible al rango de fuente de energía al servicio de lo visible. Los antiguos obligaban al tiempo a doblar la rodilla ante el trono de una eternidad que ellos mismos administraban; los modernos caminan con el tiempo convencidos de alcanzar con ello la bienaventuranza" (11).

Estas ideologías modernas recién mencionadas son una temática clave para entender el rol de Heidegger en nuestro autor. En efecto, la radical finitud del hombre concreto, desconocida u obviada por las ideologías (por ejemplo, el marxismo), se expresa particularmente en el talante temporal de su existencia dominada por el carácter inevitable de la muerte (Sein zum Tode) (12). Balthasar añadirá todavía que esta concepción no solamente frente a la muerte en general, sino frente a mi propia muerte -y que nosotros encontramos en Heidegger- permite un verdadero diálogo con el cristianismo (13).

(10) Cf. H. U. von Balthasar, Prometheus. Studien zur Geschichte des deutschen idealismus, Heidelberg 1947.

(11) Das Ganze im Fragment, Einsiedeln ${ }^{2} 1990,11$ (El todo en el Fragmento. Aspectos de Teología de la historia, Madrid 2008, 11).

(12) Cf. Theodramatik III, 83-84 (92).

(13) Cf. ibid., 112-114 (91-95). 
Es importante aludir al inicio de nuestras reflexiones, que más allá de las referencias puntuales que aquí analizaremos, que Balthasar lleva a cabo del filósofo alemán en la Teodramática, se puede captar una fina sintonía entre ambos en el hecho que sus planteos y tanteos se sienten partícipes de la superación de la neoescolástica (y con ello la ontoteología) en sus respectivos quehaceres, y sobre todo en la superación de la idea de "substancia" como elemento directriz de la realidad y por ende de todo el pensar. Esta "superación" se ve en el hecho de poder descubrir en la cotidianeidad, en el evento de la vida fáctica, en el acontecer temporal, las huellas, "analogías" (Balthasar), "señales" (Heidegger) de aquello que causa el "arrobamiento" y asombro que están al inicio de la fe y la filosofía. Nos referimos así a la aparición de lo incondicionado que me dispone en mi historia, en mi tiempo, en el "gran teatro del mundo", por lo que palabras como acción, acontecer, evento, cobran un calado muy distinto y decisivo en relación a la pregunta por la verdad, lo real, etc. que poseían en la neoescolástica. En el caso de Balthasar, esta vuelta a una filosofía de corte más fenomenológica (14), si se me permite, le ofrece la ocasión de dar mejor cuenta, en el lenguaje humano, de forma mucho más justa, de varias dimensiones claves: la revelación de Dios en la historia, atestiguada por las Escrituras y la tradición histórica de la cual el teólogo es ya parte, del drama patético, del carácter "urgente" que cobra el tiempo frente al hombre entre la primera y segunda venida de Cristo, de la Pascua, del seguimiento, la historia de la Iglesia, etc. Todo esto le da la posibilidad, sobre todo, de pensar la revelación como manifestación de la figura (Gestalt) verdadera de Dios y con ello del hombre en el drama del mundo, cuyo núcleo es "la acción" vertical que se puede reconocer en el plano horizontal del mundo creado y predispuesto a recibir el don. En relación a los trascendentales clásicos, estos se entienden no de forma estática o atemporal, sino desde la acción de Dios en la historia y la respuesta humana derivada de ella: por ello el bonum, está al medio del Tríptico, pues le da su carácter y textura definitiva a los otros. Por ello, una filosofía que le permita a la teología entender e interpretar a fondo la dimensión horizontal del teo-drama, tiene valor "teológico", desde el momento en que en ese plano se revela Dios, al interior de las coordenadas que lo conforman, y que, en el caso de Hiedegger, le permite a Balthasar pensar a aquellas como tiempo, historia, finitud, cotidianeidad, pathos y premura por parte de la libertad a decidirse: o toma parte por la autoafirmación y conocimiento titánico de sí, o de reconocerse regalada, donada por Dios. Y como esto pasa en el drama real de la historia y no en otro mundo o el mundo de las ideas, los análisis fenomenológicos sobre el presente cobran un estatuto epistemológico propio al interior de la misma teología.

Luego de la referencia que hemos hecho a la obra cumbre de Heidegger en la Teodramática, nos referiremos en lo que viene a la segunda referencia balthasariana al pensamiento del filósofo alemán y de su obra titulada Nietzsche.

(14) Cf. J. Greisch, Un tournant phénomenologique de la theologie?, Transversalités 63 (1997), 75-97. 


\section{LA INTERPRETACIÓN DEL CARÁCTER DESTINAL DE LA TÉCNICA MODERNA DEL NIETZSCHE DE HEIDEGGER EN LA ACCIÓN}

Balthasar hace referencia al Nietzsche (1961 (15)) de Heidegger al interior de la sección que sigue a la cual nosotros acabamos de examinar. Aquí se ve muy bien el carácter táctico, al que aludíamos anteriormente, de las citas de Heidegger, pues a pesar que cuantitativamente estas citas en referencia a Nietzsche parecen poco relevantes al interior de la Teodramática, ellas juegan un rol hermenéutico muy importante, pues permiten explicitar mejor la relevancia del evento divino, del acontecer de Dios en el plano "horizontal" del drama, de cara a un punto clave de todo el andamiaje balthasariano, como lo es la exigencia de alteridad frente al acontecer de Dios como constitutivo para una interpretación adecuada de hombre, mundo y ser.

Esta sección ilustra las relaciones existentes entre libertad, poder y mal al interior del mundo moderno de la tecnociencia. Esta referencia se encuentra más precisamente en el capítulo consagrado al poder (Macht), donde se habla de la hegemonía conquistada de la racionalidad técnica: "Esta estructura de poder, que es propia del ser humano en cuanto personal y social y que nunca fue seriamente impugnada en las antiguas culturas, choca en el mundo moderno no sólo en el ámbito político, sino continuamente con la instauración de la hegemonía de la razón instrumental, que se orienta primariamente a disponer de la naturaleza y que, en este sentido, al reducir la naturaleza a mera facticidad, puede renunciar al polo personal de reconocerse-debido (Verdankung) al bien, con lo que se entiende y ejerce como puro instrumento de poder. La demostración de Heidegger de que la metafísica moderna alcanza su cima en la voluntad de poder de Nietzsche (desde donde queda desenmascarada toda su evolución) no puede, en cuanto la descripción más desnuda de la situación, ser dejada de lado" (16).

Así, el análisis heideggeriano de Nietzsche expresa las consecuencias de la dominación total de la tecnociencia y la idea de mundo y hombre que ella implica. En esta obra Heidegger no pretende un análisis académico de este filósofo, sino sobre todo darnos pistas sobre su propio programa ontológico que siempre habla del "ser".

Ahora bien, y esto es muy importante para nuestro análisis, si para el filósofo alemán la "dominación" a la que aludimos pertenece al dominio del "olvido del ser" (Seinverlassenheit) y su horizonte destinal, tema por cierto decisivo en esos años para este pensador, para Balthasar, al contrario, este proceso histórico está directamente unido al olvido culpable por parte de la libertad finita de su "ser donado" (Geschenktsein), de su ser en alteridad (lo que finalmente es la negación de la gracia). En relación a esto, comentando un texto de Nietzsche, Balthasar escribe a propósito de la libertad humana: "Aquí se alcanza la máxima radicalidad: el polo de la libertad humana, que tiene que reconocerse debido a una libertad infinita y su benevolencia regia, se convierte, en unión de esta benevolencia, en una función de la autonomía o de un poder cada vez mayor; hace surgir de sí misma todo lo que

(15) Nietzsche, vols. 1-2, Pfullingen 1961 (hay traducción al español). En la Gesamtausgabe se pueden ver los volúmenes 6.1 y 6.2; además es interesante ver también los volúmenes 43, 44, 46, 48, 67 y 87. Cf. supra la literatura secundaria citada en nota 5.

Theodramatik III, 143 (144). 
signifique benevolencia". Y un poco después afirma: "Contra esta incapacidad de recibir, que es para Heidegger la marca de una época para la que todo se ha convertido en 'factible', ha elaborado una filosofía en la que 'la esencia del hombre se determina a partir de la esencia (verbal) de la verdad del ser por el ser mismo', de modo que el hombre en la radicalidad de su estructura receptiva tendría que existir para la riqueza y la pobreza del ser como agradecimiento de que el ser 'se dé"” (17). Y más adelante afirma: "Detrás de esta filosofía se esconde lo mejor de una filosofía de la libertad (ya a nivel natural y consumado en el cristianismo) que no niega el encargo dado al hombre de dominar la tierra, pero que lo conecta esencialmente con la idea de Dios, a partir del cual puede configurar la tierra de un modo fecundo y pleno de sentido" (18).

Esta última cita nos muestra pues el rol táctico de las citas heideggerianas en Balthasar: a través de ellas aparece como lo más propio del hombre el recibir, en su ser criatura, en alteridad (venciendo la tentación tan típica de la tecnociencia de autarquía y autoconstrucción), la oferta de un Dios que se ofrece como digno de una acción de gracias, lo que revela al hombre sobre todo como ser agradecido y responsorial -y no titánico- frente a la figura de Dios que se revela en el drama de la historia.

\section{EL ESCLARECIMIENTO DE LOS VÍNCULOS ENTRE LAS DIMENSIONES HORIZONTAL Y VERTICAL DEL TEO-DRAMA A LA LUZ DE LA FILOSOFÍA DE HEIDEGGER}

En lo que hemos dicho sobre el contenido, la lógica y estructura formal de la Teodramática y de su lugar en el ensamble de la Trilogía, se ha mostrado ya la importancia estructural -y hermenéutica- de las referencias que hace Balthasar de Heidegger. Estas proveen el contenido mismo de la dimensión horizontal del evento global que compone la Teodramática (19). Desde este punto de vista, estas referencias son esenciales para la comprensión de la arquitectura y meta de la Teodramática. En efecto, en acuerdo con el rol absolutamente decisivo que juega la "voluntad de poder" en la técnica moderna, Balthasar no atribuye esta voluntad al poder de un destino metafísico impersonal (que me adviene), sino que la pone en relación responsable con la libertad finita concreta, que, en lugar de reconocer y admitir su autonomía como un don de Dios que la constituye persona, ek-sistencia (Ricardo de San Víctor), como una autonomía en alteridad, como libertad liberada, y que es así legítima e irreversiblemente desarrollada gracias a esta misma técnica, decide olvidar este "ser donado" (Geschenktsein) que la funda ontológicamente como un ser libre que en la historia se realiza como personaje del drama (las reflexiones que el teólogo suizo lleva a cabo en la Teodramática sobre el "pecado original" y su perenne actualidad salvífica para el hombre están en estrecha relación con esta temática; creemos que esta forma de repensar el contexto del pecado original hace que lo esencial de su doctrina pueda

(17) Ibid., 145 (146).

(18) Ibid., 145 (146-147).

(19) Cf. M. Imperatori, Heidegger dans la "Dramatique divine”, 198ss. 
entrar en diálogo fecundo con importantes preguntas filosóficas y culturales hoy en día, sobre todo con la posibilidad del hombre de construirse de espaldas al Don, a lo no merecido que lo realiza de forma plena).

Pensamos que la temática del "ser donado" nos conduce a otra muy relevante del pensamiento teológico-metafísico de Balthasar, como lo es la "alteridad". Desde sus estudios tomistas, la "alteridad" es un descubrimiento clave para una auténtica comprensión del ser y del hombre, sobre todo la alteridad con Dios. Así, frente al olvido del ser, creemos que además de subrayar la temática del "ser donado", hay que remitir a la de la "alteridad" personal para entender una diferencia clave entre el planteo de Balthasar y Heidegger.

De esta forma, el hombre no está simplemente confrontado a un impersonal destino epocal caracterizado como "olvido del ser", sino más bien a una verdadera "voluntad humana de negación" (20) (así la "culpa" no es tanto olvido de ser, sino negación de la gracia, de la oferta de alteridad personal que me construye como libertad destinada a Dios). Si para Heidegger el Gestell (21) es el lugar extremo donde el hombre puede entender eventualmente el llamado del ser antes de zozobrar en la tentación totalitaria inherente al uso y al desarrollo de la técnica, para la teología balthasariana este mismo Gestell puede significar el fin de la humanidad, víctima de una "voluntad de poder" siempre más grande, y así, sobre todo, "un inesperado reencuentro con la dimensión vertical de la historia en el sentido que lo presentó

(20) Theodramatik III, 146 (147).

(21) Al provocar que emplaza al hombre a desvelar las cosas como existencias lo denomina Heidegger Gestell. Se trata de una palabra del lenguaje corriente (significa armazón, dispositivo) a la que Heidegger une nuevas connotaciones, hasta hacerla significar, no un utensilio sino la esencia de la técnica. Gestell es "imposición" o armazón que impone un modo de desocultar; "dispositivo" que dispone de hombres y de cosas, que pone al hombre a poner las cosas como lo disponible; "composición" que reúne a hombre y Ser en las figuras de demandante y existencias. Gestell designa, en suma, el hacerse patente del Ser en la forma del desafío y comprende lo que conocemos como planificación, organización. Esta descripción del Gestell permite ver que quien impone no es el hombre. El hacer humano se sostiene sobre el provocar del "dispositivo", el cual impone la técnica al hombre como modo del desocultar. Que el hombre se dedique a planificarlo todo es a causa del dispositivo/ imposición. Éste empuja al hombre a planificar, convirtiendo a los hombres mismos en elementos del plan universal que dirige las realizaciones de la técnica. El Gestell pone en juego una dimensión de lo técnico que no es humana. Este es el contexto de ideas del que forma parte la conceptuación del dispositivo/armazón como destino. Porque el operar humano con la técnica pertenece al ámbito del "dispositivo", pueden hacerse afirmaciones como ésta: "siempre prevalece, de parte a parte, en el hombre el sino del hacer salir lo oculto" (M. Heidegger, La pregunta por la técnica, en Conferencias y artículos, Barcelona 1994, 26). En la técnica actúan automatismos que tienen su origen en un destino. Es necesario, por ello, superar la representación de lo técnico como algo presente, para elevar la mirada a la esencia de lo técnico, la cual, desde la ausencia y desde el estado de ocultamiento, interpela en forma de destino al hombre; hay que pasar de la comprensión de la técnica a partir del hombre y de las máquinas a prestar atención al destino que nos habla en la esencia de la técnica (cf. id., Identidad y diferencia, Barcelona 1988, 81). El dispositivo coloca al hombre en el camino de un desocultar que hace aparecer a las cosas como existencias. Dado que poner en un camino es lo mismo que enviar (schicken), al envío que pone al hombre en el camino del desocultar se le llama destino (Geschick). Empujándole a requerir la "imposición" (Gestell), envía al hombre a desocultar y cae sobre lo humano como un envío (Schickung) del destino (Geschick). De un destino que proviene del destinar del Ser. La imposición es un destino del Ser, porque es el mismo Ser el que se nos envía en el Gestell bajo rostro de una maquinación generalizada (cf.A. Pérez, Técnica, ciencia y metafísica según Heidegger, Seminario "Orotava” de historia de la ciencia, año IV, 79-102). 
el Apocalipsis en sus enigmáticas imágenes" (22), tal cual ella constituye el objeto principal de la primera parte de La acción. En esta perspectiva, la Teodramática se presenta como la respuesta, o mejor propuesta teológica, al análisis filosófico de la emergencia planetaria de la técnica formulada por Heidegger en su obra Nietzsche y como un servicio rendido a aquel "inesperado reencuentro con la dimensión vertical de la historia" que se despeja a partir de esta misma emergencia (23). Es así pues que el acontecer de Dios revela las honduras de la dimensión horizontal, y una correcta hermenéutica de ésta se vuelve ocasión para descubrir un ámbito de inserción de la revelación.

Ahora acometeremos la tarea de ver cómo esto último se concretiza en la última parte de La acción, donde encontramos una temática transversal a toda la obra de Balthasar como lo es el Apocalipsis y la apocalíptica.

\section{UNA PERSPECTIVA ESCATOLÓGICA DEL PRESENTE}

En la última parte de La acción se afirma que la Iglesia deberá realizarse en un tiempo final semejante, análogo, a la "hora" experimentada por Jesús en el fin de su misión terrestre; es decir, un tiempo de prueba caracterizado por el abandono por causa de la apostasía de la fe y el ateísmo. Este es un elemento fundamental de la parusía final. Hay que precisar, que esta tesis balthasariana no implica en ningún caso la existencia de un paralelismo riguroso -y necesario- entre las diferentes etapas de la vida terrestre de Jesús y la historia de la Iglesia, porque toda la vida de Jesús, muerto y resucitado una vez para todos, está ya escatológicamente presente en todo momento de la historia de la iglesia como de la historia de todo cristiano. Toda la vida de Jesús está así prolépticamente presente. Se puede decir de este modo que la existencia entera de Jesús y sus misterios, que el Señor resucitado, se anticipa en el curso de la historia en la iglesia. En ningún momento la afirmación de la existencia de la parusía final debe entonces ser separada de la constante presencia aconteciente del crucificado y resucitado a lo largo de la historia de la iglesia (la misma etimología y significado de la palabra parusía al interior del Nuevo Testamento es saludablemente ambigua, pues a veces designa la primera venida de Cristo y a veces la segunda, con lo que hablar así de "primera" y "segunda" no es correcto si con ello se quiere establecer una separación clara y distinta). Aquí se trata así de una interpretación del tiempo final que se aprecia rigurosa y explícitamente cristológica, sin por tanto caer en una simple "escatología realizada" -como la de Ch. Dodd- que terminaría por destruir la consistencia y textura propia de la historia de la Iglesia y del mundo.

En este sentido, la "prueba final" de la que habla Balthasar es una consecuencia de la universalización del "poder" de Jesús (el poder del reino) y que provoca y desencadena una oposición siempre mayor a su misión terrestre, revelando así la profundidad del mal y del pecado desenmascarada por este poder al asumir y por último destruir en el triduo pascual a aquellos. Esto es lo que Balthasar llama continuamente "la ley teodramática de la historia".

(22) Cf. Theodramatik III, 80 (88).

(23) Cf. ibid., 60-63 (63-66). 
He aquí un texto balthasariano significativo a propósito de lo que venimos señalando: "La fase final de la historia de la iglesia se corresponde así con el final de la vida de Jesús, el que 'dio testimonio ante Poncio Pilato con tan noble profesión' (1 Tim 6, 13); y este paralelismo, como queda dicho, no tiene en absoluto fundamento en la apocalíptica judía, sino que es de cuño pura y simplemente cristológico" (24). Y un poco más adelante nuestro autor precisa: "En la época en que la Iglesia habrá terminado la etapa de la misión, en la que ha ido fecundando con su sangre a sus nuevas plantaciones (como lo muestran los Hechos de los Apóstoles, que son el paradigma de todos los tiempos de misión); ahora, entra definitivamente en la fase de compasión con Cristo, en donde éste afronta de una manera totalmente nueva el mysterium iniquitatis, para despojarle, interiormente, de su poder por la fuerza del sufrimiento mantenido consecuentemente: 'Porque cuando soy débil, entonces soy fuerte' (2 Cor 12, 10)" (25).

La parusía así descrita implica de esta forma una dimensión escatológica no solamente en razón de su fundamento cristológico, sino a causa de la imposibilidad nuestra para determinar con certitud el carácter intrahistórico o escatológico de ciertos nombres de eventos que la Escritura narra, sobre todo los apocalípticos y proféticos. La frontera entre la dimensión horizontal y la dimensión vertical, entre historia y escatología, pasa ciertamente por el fenómeno de la parusía final, mas al punto que se mantendrá para nosotros siempre misteriosa. La soberanía y majestad de Dios son el horizonte final de interpretación de la parusía. A pesar de la radicalización de la "ley" teodramática de la historia, nosotros estamos al interior de la tensión entre el "ya" y el "todavía no" evangélico, que no será completamente abolido sino al momento del desarrollo total de la parusía final -así por ejemplo el "anticristo" es todo poder idolátrico que se enfrente al poder de Dios revelado en Cristo en la historia, que pida para sí adoración, con lo que la parusía final se anticipa también en el presente, por lo que la escatología es verdadera "teología de la historia", por ocupar una idea muy cara a Balthasar. En parte este "no saber" es constitutivo de nuestra libertad.

¿Cómo integra Balthasar en el horizonte teológico lo que hemos presentado sumariamente a propósito de la interpretación heideggeriana de la técnica? Balthasar inserta esta interpretación al interior de la dialéctica paulina de los "dos Adanes" que ya estaba presente en los análisis antropológicos anteriores de la Teodramática. En esta perspectiva, la secularización técnica, la emancipación y la autonomía del hombre que ella presupone y contribuye a acrecentar, son dos fenómenos históricamente irreversibles. Ellos están conformados a un proyecto, con clara influencia de Ireneo, cristocéntrico que precede a la creación divina del mundo. Balthasar subraya fuertemente la ambigüedad que acompaña a estos fenómenos en el plano histórico a causa del pecado del hombre y del misterio del mal al cual están ligados. Desde esta óptica, el desarrollo de la técnica moderna, a la cual el cristianismo ha contribuido desde largo tiempo en razón de su concepción del carácter profano del mundo, y de una relativa autonomía, sobre todo en su interpretación de los primeros capítulos del Génesis, podría desembocar de sí en la afirmación de una autonomía humana siempre más cristoforme y teocéntrica, en alteridad, como la hemos llamado con anterioridad,

(24) Ibid., 417-418 (419).

(25) Ibid., 419 (421); cf. M. Imperatori, Heidegger dans la "Dramatique divine”, 200ss. 
para iluminar el "misterio del mal", que para Balthasar es ante todo la voluntad de construirse de espaldas a Dios. El desarrollo de la técnica moderna deviene así la ocasión de un combate, una lucha siempre más dramática entre el llamado a la libertad, siempre más cristoforme y teocéntrico del nuevo Adán, y la tentación del viejo Adán de atribuirse a sí mismo el fundamento de su autonomía, de la ciencia, de romper con la alteridad que lo mantiene y recrea, en rechazar la gracia, en hacerse Dios -y por tanto ídolo- de su propia vida (en clara consonancia con el "encorvarse en un mismo" como define Agustín el pecado); combate que se acentúa a medida que la parusía final se aproxima, o mejor dicho se "anticipa" (obviamente en una dimensión kairológica y no meramente cronológica del tiempo) y es así presupuesto positivo, lo cual presupone en todo caso un paso a través de la muerte. Balthasar tiene así una mirada positiva del hombre y su naturaleza, no sólo de forma abstracta, sino también en su concreción contemporánea, y, aunque no dialoga con filósofos como Habermas, pensamos que por lo menos establece un punto de partida "positivo" para el diálogo entre la teología y la modernidad, incluso a pesar de cierto pesimismo cultural presente en su obra.

Aquí surge sin embargo una interrogante muy importante: ¿evita la teología de Balthasar la inclinación fatalista y negativa que caracteriza la interpretación heideggeriana de la modernidad, en cuanto que aquella teología no rinde suficiente cuenta de los aspectos positivos ligados al desarrollo de la técnica, como lo son la emancipación, autonomía y libertad? Creemos que esta interrogante se podrá resolver en la medida que pensemos muy bien la palabra "ley" al interior de la expresión "ley teodramática de la historia" ¿Implica aquí "ley" una secuencia que ya en su inicio tiene un desarrollo predeterminado, o es posible entenderla desde una comprensión escatológica-bíblica que la libere de una lógica que no dé lugar a la sustentabilidad y autonomía del tiempo de la iglesia?

\section{UNA TEXTURA Y MODULACIÓN ESCATOLÓGICA DE LA LEY TEODRAMÁTICA DE LA HISTORIA (26)}

En este punto final nos acercamos dialógica y críticamente al planteo balthasariano, a partir de la idea de "ley" subyacente a la expresión programática "ley teodramática de la historia" (sobre todo queremos salvar aquí a la palabra "ley" de la connotación de algo irreversible, que quede más allá del uso y responsabilidad de la libertad y actuar humanos, con el peligro de poner en cuestión el carácter sustentablemente dramático, por ejemplo, del seguimiento). Otros ensayos escatológicos recientes que dan gran importancia exegética y sistemática a la parusía nos señalan algunas pistas en este acercamiento crítico a Balthasar (27). Estos ensayos contemporáneos,

(26) Cf. M. Imperatori, Heidegger dans la "Dramatique divine”, 191-210.

(27) Cf. J. Noemi, El mundo. Creación y promesa de Dios, Santiago 1996; id., Esperanza en busca de inteligencia, Santiago 2005; M. Kehl, Escatología, Salamanca 1992; P. Hünermann, Cristología, Barcelona 1997, 93-162; A. Gesché, Dios para pensar, vol. III, El Destino, Salamanca 2001; G. Klein: art. Eschatologie, en: Theologische Real-Enzyklopädie, vol. 10, Berlin-New York 270-299; W. Radl et al., art. Parusie, en: W. Kasper (ed.), Lexikon für Theologie und Kirche, vol. 7, Friburgo 1998, 1402-1405. 
algunos de los cuales mucho le deben a Balthasar, se alejan de su planteo precisamente donde ellos subrayan que el carácter dramático de la historia y sus signos actuales más catastróficos no se encuentran de cara a un proceso de "irreversible decadencia", sino que permiten al mismo tiempo rendir cuenta teológica de aspectos emancipatorios unidos a la afirmación de la técnica y de la cultura modernas, sin por ello ocultar los peligros que la técnica implica para la libertad humana. Es decir, la ciencia y cultura modernas tienen un potencial positivo en relación a la pregunta por la libertad, donde a veces es posible descubrir "impulsos" cristianos (por ejemplo, la libertad en relación a la comunión y el diálogo). Estos ensayos contemporáneos permiten repensar críticamente la idea de "ley" teodramática de Balthasar. Ella puede al mismo tiempo limitar, anular el carácter dramático que dice expresar, en la medida que manifiesta la concepción que la misión de Jesús de una parte, y la historia de la Iglesia y del mundo por otra, obedecen de alguna manera a una necesidad histórico-teológica, a una secuencia, que Balthasar rechaza (28). Esta impresión puede ser entonces reforzada por la utilización que Balthasar hace de la hermenéutica heideggeriana de la modernidad, muy influenciada por el propio contexto vital y filosófico del filósofo.

De esta forma, es necesario en vistas a la lectura crítica de Balthasar otorgarle a la expresión "ley" teodramática de la historia su verdadera dimensión bíblica y sistemática y liberarla así de toda sospecha de una secuencia lógica necesaria y comprobable de forma clara y distinta en la historia.

Se puede afirmar que el lenguaje escatológico en la Biblia no es propiamente una predicción del porvenir, una "ciencia de las cosas futuras", "una física de las cosas últimas", un mapa del futuro, que va necesariamente a ocurrir, sino la puesta en guardia, en vigilia, dirigida en nombre de Dios a la libertad humana en su "ser en el mundo", en su aquí y ahora, en vistas a su conversión, a su metanoia (29). Se trata, pues, que el hombre descubra en el llamado escatológico -incluso el género apocalíptico no tiene como fin la identificación unívoca entre acontecimientos históricos y símbolos y signos propios de ese género, por ejemplo el "anticristo", sino llamar en cada época a una conversión hacia Dios y el consecuente abandonado de los ídolos, y a una espera confiada en que el Dios que está presente en medio de la historia, aún en las catástrofes, nos saldrá al encuentro al final de los tiempos, lo que se ha anticipado con Cristo, en el caso del Apocalipsis de Juan- una voz, una convocatoria, que le permita convertir, redirigir su vida hacia aquello que le posibilitará a ésta encontrar su dimensión salvífica y redentora, que le posibilitará realizarse a cabo de forma plena. Muchas veces tiene la forma de un llamado de abandono a la idolatría.

Si nosotros (re)interpretamos a partir de esta óptica la "ley" teodramática, podríamos evaluar mejor su actualidad y pertinencia, su identidad y relevancia. Aquí no se trata tanto entonces de una "necesidad" (de tipo hegeliana), de una "secuencia", sino más bien de una escatología que describe, a partir de lo que se ha realizado en el misterio pascual de Jesucristo y cómo hacerse parte en ese mismo misterio, una

(28) Cf. Theodramatik, vol. II/2, Die Personen des Spiels: Die Personen in Christus, Einsiedeln 1978, 13 (Teodramática, vol. 3, Las personas del drama: El hombre en Cristo, Madrid 1993, 20-21).

(29) Cf. G. Savoca, art. Profecía, en: P. Rossano et al. (ed.), Nuevo Diccionario de Teología Bíblica, Madrid 1990, 1520-1538. 
posibilidad donde la realización concreta dependerá de elegir por la libertad finita del hombre de cara a los formidables desafíos que le impone la tecnociencia. En esta perspectiva, la técnica no aparece más como un destino inevitable y trágico (como en las tragedias griegas, a diferencia del teodrama, que el mismo Balthasar distingue en otro momento), aunque ella potencia en todo momento el devenir. Ella aparece como la ocasión para el hombre de ejercer una elección verdaderamente dramática entre al antiguo Adán y el nuevo Adán, entre la libertad abierta al acontecer de Dios, al evento divino, o la libertad cerrada en los límites de su finitud, en donde se revela la realidad del mal y del pecado como enclaustramiento del yo, la ruptura de comunión que cierra al evento, a la manifestación. Esto, creemos, expresa bien el espíritu del pensamiento balthasariano sobre el tema, a pesar de ciertas ambigüiedades en su argumentación y de un cierto pesimismo frente al mundo moderno (quizá de orden más cultural que estrictamente por razones teológicas). Por último hay que añadir que sólo esta interpretación escatológica -no en el sentido de una "teología del más allá" sino en una teología de un Dios que acontece anticipándose en el presente, en el acá, como futuro del hombre y la historia- de la "ley teodramática" de la historia permite el seguimiento consistente de Cristo por parte del cristiano en la historia al interior de la teodramática, tal cual lo subraya el mismo Balthasar.

En nuestros días A. Gesché se ha referido, por ejemplo, a la posibilidad de ofrecer un discurso teológico coherente de carácter "escatológico", como oferta positiva de realización plena: "Proclamar este vínculo entre Dios y el hombre es darle a éste el fundamento más absoluto y más definitivo para que pueda respetar y hacer que se respete su absoluta dignidad. Res sacra homo, el hombre es una cosa santa. Esa es la profecía divina" (30). Es decir, lo escatológico nos confronta con la propia historia y la "abre" como teodramática.

El quehacer teológico, por tanto, deberá estar siempre atento a no caer en una visión unilateralmente negativa del tiempo actual (31) (la lectura de Ladrière, Hünermann y Noemi nos enseña a saber descubrir también el carácter escatológico y positivo -de raíz judeo-cristiana- inherente a la técnica moderna), ni menos adjudicar sin más símbolos y signos del Apocalipsis de forma negativa al mundo tecnocientífico actual. El tiempo de la técnica y la ciencia, más allá de la necesaria crítica, se revela así como un ámbito de inserción privilegiado de la fe para la misión de la iglesia, pues estos ámbitos no son sólo negatividad y cerrazón frente a la posibilidad del lenguaje religioso, sino que a su interior se puede y debe descubrir una dinámica de preguntas escatológicas, de interrogantes por la libertad del hombre y por una vida lograda. Incluso se debe ver positivamente el hecho de la emancipación. De esta forma la dimensión "dramática" del tiempo de la iglesia, la época del seguimiento, podrá ser así mucho mejor valorada.

Un bello texto nos puede iluminar en relación al carácter positivo de la razón técnica actual como desafío para la teología: "La razón, como proceso de su autoconstitución, siempre adveniente y diferida, pende del acaecer no justificable, no figurable, no representable de lo que podría revelar su sentido, de lo que ahora le da efectivamente dicho sentido. Ella es la esperanza de aquello mismo que, desde su futuro no

(30) Jesucristo, Salamanca 2002, 45.

(31) Cf. J. Noemi, Esperanza, 37-58. 
situable, la sostiene en cuanto esperanza. En una palabra, la reflexión acerca de las modalidades de constitución de la razón científica nos lleva a concebir la estructura de la razón como estructura escatológica. Su despliegue actual está dependiendo como anuncio de un acontecimiento siempre por venir, ya presente y, sin embargo, siempre esperado, en la fragilidad de una esperanza no fundamentada" (32).

\section{CONCLUSIÓN}

Las analogías en relación a la importancia que tiene el evento y el tiempo en los planteos de Balthasar y Heidegger, en vistas a las preguntas fundamentales sobre el ser y Dios, me parece digno de seguir. Así, por ejemplo, como lo plantea B. Körner (33), para Balthasar la revelación no es primariamente una "palabra aislada", o un "punto", sino, en palabras del autor de la Trilogía "superficie", "tiempo", "espacio", "figura". Entendido de esta manera, reflexionar sobre el significado del evento revelatorio salvífico, tarea primordial del teólogo, se decide sobre todo en la hermenéutica que realicemos, obviamente en perichoresis con los demás trascendentales, del bonum, del teodrama, de la dramática de las libertades, etc., temáticas que constituyen el centro, el núcleo, del pensamiento balthasariano. Así, el diálogo fecundo con Heidegger no sólo le otorga al teólogo un instrumental conceptual con el cual interpretar la dimensión "horizontal" del drama, sino que si ésta ya tiene una precomprensión teológica, la filosofía heideggeriana permite acercarse mejor a la textura metafísica del ser creado, que, más allá de los límites de aquel planteo, permiten vislumbrar que lo propio del ser creado se verifica en su relación, en el tiempo y el espacio creado, con un Dios que acontece regalándose como Don de la redención que debe ser aceptado en el tiempo, que en la era poscristiana deriva en la lucha permanente con la "tentación" de darle a la existencia un significado final desde la absolutización del yo y de lo que "está a la mano" (34).

La idea balthasariana de una existencia humana no abierta a la gracia, a la alteridad, como lo esencial del pecado personal y original, se podría ver enriquecida por la idea de Heidegger del olvido del ser y una existencia volcada a la técnica y a lo que está a la mano. Una lectura crítica además permitiría reconocer los elementos positivos (y teológicos) de la ciencia y técnica moderna y alejar la reflexión teológica de todo peligro de determinismo y fatalismo.

(32) J. Ladrière, Le christianisme et le devenir de la raison, en: Christianisme et modernité, Paris 1990, 217-218.

(33) Cf. Fundamentaltheologie bei Hans Urs von Balthasar, eitschrift für Katholische Theologie 109 (1987), 129-152.

(34) Para seguir el diálogo, dentro de la inmensa literatura reciente, remito a dos participantes del congreso que están publicados en este número. Además de sus artículos, cf. D. C. Schindler, „Wie kommt der Mensch in die Theologie?" Heidegger, Hegel, and the Stakes of Onto-theo-logy, Revista Española de Teología 65 (2005), 437-465; id., Hans Urs von Balthasar and the Dramatic Structure of Truth: A Philosophical Investigation, New York 2005; M. Schulz, A través de la nada de la angustia de Dios, “Pastor del ser”, Espíritu 116 (1999), 169-181. 


\title{
RESUMEN
}

En este artículo se desarrolla la influencia táctica de Heidegger en Hans Urs von Balthasar, especialmente en "La acción". La influencia se ve en dos niveles. Primero de la obra "Ser y tiempo" en la comprensión balthasariana de la temporalidad y finitud, como característica básica -y olvidada a veces- del hombre, que sólo así puede estar abierto a la revelación. El segundo nivel es la obra "Nietzsche" del filósofo de Friburgo. Es sobre todo esta última obra la que le ayuda a Balthasar a pensar a Dios como "acontecimiento", evento gratuito plenificador del hombre. Hay así al interior de la dramática una cierta "analogía" entre la crítica "al olvido del ser" y al "olvido del reconocerse donado", actitud básica del hombre, según Balthasar, frente a la iniciativa de Dios de regalarse, en alteridad, para salvarlo en su temporalidad e historia.

Palabras clave: Balthasar, Heidegger, acontecimiento, don, acción, temporalidad, alteridad.

\begin{abstract}
In this article, an examination of the tactical influence of Heidegger upon Hans Urs von Balthasar is developed, especially in the theo-drama The Action. This influence is seen on two levels. First, in the work Being and Time on the Balthasarian understanding of temporality and finitude as a basic characteristic -sometimes forgotten- of the human person, who only in this manner can be open to revelation. The second level is the work Nietzsche by the Freiburg philosopher. It is above all this latter work that helps Balthasar to think of God as "event", a gracious fulfilling occurrence of the human person. Thus there exists in the interior of the dramatic a certain "analogy" between the critical "forgetting of being" and the "forgetting of recognizing oneself as given", a basic attitude in the human person, according to Balthasar, when faced with God's initiative of giving Himself as gift, in alterity, in order to save him in his temporality and history.
\end{abstract}

Key words: Balthasar, Heidegger, event, gift, action, temporality, alterity. 
